\title{
Laparoscopic Anterior Resection with Anastomosis of Mid- Transverse to Distal Rectum with Deloyers Procedure Under Indocyanine Green fluorescence Guidance: A Video Case Report
}

\author{
Qi Tian Teo, MBBS (S'pore), MRCS (Edin) (1), Frederick H. Koh, MBBS (S'pore), MRCS (Edin), MMed (Surg), \\ FRCS (Edin), FAMS (Surg), Jasmine Ladlad, MD, MRCS, Fung Joon Foo, FRCS (Edin), and \\ Ming Li Leonard Ho, MBBS (S'pore), MRCS (Edin), M Med (Surg), FRCS (Edin)
}

Colorectal Service, Division of Surgery, Sengkang General Hospital, Singapore, Singapore

\begin{abstract}
Background. Reconstruction with transverse colon-rectal anastomosis after an extended left hemicolectomy can be challenging. The Deloyers procedure, first described in 1964, ${ }^{1}$ comprises complete mobilization and rotation of the right colon, while maintaining the ileocolic artery, to achieve a well vascularized, tension-free colorectal anastomosis. We present a video of a laparoscopic Deloyers procedure with Indocyanin green (ICG) fluorescence as a useful adjunct.

Methods. A middle-aged female underwent a laparoscopic anterior resection with anastomosis of mid-transverse to distal rectum with Deloyers procedure for synchronous splenic flexure adenocarcinoma and mid-rectal malignant polyp. Proximal transection was performed at mid-transverse colon while distal transection was performed at lower rectum. Tension-free mid-transverse colon-low rectal anastomosis was performed with Deloyers procedure. ICG fluorescence was performed for the colonic conduit, proximal, and distal transection margins to confirm perfusion just prior to anastomosis. Defunctioning loop ileostomy was then created $40 \mathrm{~cm}$ from the ileocecal valve.

Results. Patient recovered uneventfully with functioning stoma on postoperative Day 1. Intraoperative use of ICG fluorescence has been proven to be an accurate tool assess anastomotic perfusion and has been associated with a lower
\end{abstract}

(C) Society of Surgical Oncology 2022

First Received: 6 August 2021

Accepted: 16 January 2022;

Published Online: 18 February 2022

F. H. Koh, MBBS (S'pore), MRCS (Edin), MMed (Surg), FRCS (Edin), FAMS (Surg)

e-mail: frederick.koh.h.x@singhealth.com.sg anastomotic leak rate after colorectal resection. ${ }^{2}$ To our knowledge, this is the first report in which laparoscopic Deloyers procedure was performed under ICG guidance. Open Deloyers procedure with ICG was first reported by Okamoto et al. ${ }^{3}$ in April 2021 and remains the only other case report of Deloyers with ICG to date.

Conclusions. The Deloyers procedure can be safely performed laparoscopically and ICG fluorescence is a recommended adjunct to assess such unorthodox colorectal anastomosis.

Supplementary Information The online version contains supplementary material available at https://doi.org/10.1245/s10434022-11373-y.

DISCLOSURES Fung Joon Foo-received an honorarium from Johnson and Johnson for giving a talk on Webinar about inflammatory bowel disease (unrelated).

\section{REFERENCES}

1. Deloyers L. Suspension of the right colon permits without exception preservation of the anal sphincter after extensive colectomy of the transverse and left colon (including rectum). Technique-indications-immediate and late results. Lyon Chir. 1964;60:404-13.

2. Lin J, Zheng B, Lin S, et al. The efficacy of intraoperative ICG fluorescence angiography on anastomotic leak after resection for colorectal cancer: a meta-analysis. Int $J$ Colorectal Dis. 2021;36:27-39. https://doi.org/10.1007/s00384-020-03729-1.

3. Okamoto K, Emoto S, Sasaki K, et al. Extended left colectomy with coloanal anastomosis by indocyanine green-guided Deloyers procedure: a case report. J Anus Rectum Colon. 2021;5(2):202-6. h ttps://doi.org/10.23922/jarc.2020-097.

Publisher's Note Springer Nature remains neutral with regard to jurisdictional claims in published maps and institutional affiliations. 